not seem highly probable that the nations of the world are yet prepared to accept any particular scheme, though some reform on the lines indicated in this book would certainly simplify matters in many ways. At the end of the book there is a short table which enables the reader to determine the day of the week by the Julian Calendar, A.D. 1-2099, or by the Gregorian Calendar, A.D. 1582-2099.

\section{Lung Cavities in Pulmonary Tuberculosis}

Dr. Alfonso R. Sims contributes a paper on the spontaneous healing of cavities in tuberculosis of the lungs to Aparato Respiratorio y Tuberculosis, No. 3, 1944, published in Santiago De Chile, in which he gives the results of investigations carried out during the period 1937-42 at the Laenec Sanatorium, when 1,130 cases were dealt with. Males only were admitted-adolescents and adults-and it was found that spontaneous cures amounted to only 8.71 per cent. The importance of the size of the cavity was recognized and cures were not effected in cases where the diameter of the cavity exceeded $4-5 \mathrm{~cm}$. It is remarkable that cavities in the left lung showed a greater tendency to heal spontaneously than those in the right lung. Schminke's classification of the cavities as primary, secondary and tertiary, the first having three and the second two subdivisions, was adopted, and it was found that by far the greatest number of spontaneous cures took place with the first class. Infra-clavicle cavities provided the greatest percentage of spontaneous cures, and those at the apex seldom provided any. It is pointed out that great care is necessary before taking any risks in the treatment of pulmonary tuberculosis, and in all cases the patients should be dealt with while they are confined to bed, or at least under the best possible conditions of repose.

\section{Influenza Epidemics in the United States}

According to Selwyn D. Collins, head statistician of the United States Public Health Service (Public Health Rep., 59, 1483 ; 1944), in the eighteen major or minor epidemics of influenza that have occurred in the United States since the beginning of 1918, there has been great variability in the age curve. In the recent outbreak, the curve was in general similar to that of 1928-29 except for a very high incidence among children less than ten years of age. Pneumonic incidence in the current epidemic was far below that of 1918-19. Among persons less than twenty-five years of age the pneumonic rate was less in the current epidemic than in any of the others, but above twenty-five the rates corresponded closely to those recorded for the epidemic of 1928-29. The percentage of the total cases which were complicated by pneumonia in the 1943-44 epidemic was far below the figure for any other epidemic for which figures were available. In most of the epidemics the rates for influenza were consistently higher for females than for males, particularly adult females, with the exception of the 1918-19 epidemic and the minor outbreak of 1940-41, in which there were no obvious sex differences.

\section{Cooper Centenary Fellowships for Veterinary Parasitology}

The Veterinary Educational Trust announces that Cooper Centenary Fellowships have been awarded to Mr. J. F. A. Sprent and Mr. J. Hobart. The Fellowships were established with the Trust by Messrs. Cooper MeDougall and Robertson to assist in the development of veterinary parasitology, and also as a mark of the centenary of that Company. They are normally tenable for one, two or three years, depending upon satisfactory progress in the research undertaken. Mr. Sprent qualified as a veterinary surgeon at the Royal Veterinary College in 1939 and took a B.Sc. degroe in zoology with first-class honours at Birkbeck College in 1942. Since then he has been a veterinary research officer in the Colonial Veterinary Service, stationed at Vom, Nigeria, where he has carried out important investigations upon helminth infestation of cattle in that country. $\mathrm{He}$ hopes to continue to work upon helminth infestations of domestic animals with particular reference to host resistanee and the development of a host immunity. Mr. Hobart took a B.Sc. degree in zoology with first-class honours in 1943 at University College, London. He has been a demonstrator in zoology at the University College of North Wales, Bangor, and has carried out research upon the ecology of adult sheep blowfies in North Wales. His field work has comprised the trapping of flies in the field and the study of the Dipterous succession in small carcases. This work was commenced in collaboration with the Entomological Unit of the Agricultural Research Council. Mr. Hobart proposes to continue his field work in North Wales and to work upon the physiology of insects at the London School of Hygiene and Tropical Medicine.

\section{Comets}

A telegram from Dr. Harlow Shapley announces the rediscovery of Comet Pons Winnecke on May 3, its magnitude being 14. A definitive orbit for this comet was computed by Mr. J. G. Porter and members of the Computing Section of the British Astronomical Association, and an ephemeris is given in the "Handbook" for 1945. The correction to the computed perihelion is $+2 \cdot 6$ days, and the result must be considered very satisfactory as the comet passes just over $0 \cdot 6$ unit from Jupiter, suffering considerable perturbations. Dr. Shapley has also announced the rediscovery of Comet Kopff on May 7d. 9h. 10m., U.T., its magnitude being 13. An orbit and ephemeris were computed by Messrs. W. E. Beart and W. P. Henderson and are given in the "Handbook" of the British Astronomical Association for 1945. A correction of about $-8 \mathrm{~m}$. in R.A. to the ephemeris is indicated from the observation.

\section{Announcements}

The Catherine Wolfe Bruce Medal (commonly called the Bruce Medal) for 1945 of the Astronomical Society of the Pacific has been awarded to Prof. E. A. Milne, Rouse Ball professor of mathematics in the University of Oxford, for "distinguished services to astronomy". The medal is awarded on the recommendation of the directors of six observatories, of which two are in Europe. Previous British holders of this Medal have been Gill, Huggins, Dyson, Eddington, Turner, A. Fowler and J. S. Plaskett.

Prof. N. R. De ar, formerly professor of chemistry in the University of Allahabad, has given the University of Calcutta an endowment of approximately one lakh of rupees (about $£ 7,500$ ) for "perpetuating the memory of Acharya Sir Prafulla Chandra Ray and in furtherance of establishing a University College of Agriculture". Prof. Dhar states that he hopes to make a further donation of similar amount at a later date. 